\title{
MUDANÇAS CULTURAIS NA EDUCAÇÃO E O NOVO PARADIGMA BASEADO NAS TECNOLOGIAS DE INFORMAÇÃO E COMUNICAÇÃO
}

\author{
${ }^{3}$ Alderita Almeida de Castro \\ ${ }^{4}$ Elisângela Lima de Andrade Bogéa \\ ${ }^{5}$ Priscila Salazar Dauer Fagundes \\ ${ }^{6}$ Vanessa Maraes Silva
}

\section{Resumo}

O presente estudo traz à discussão reflexões sobre o surgimento de um novo paradigma, baseado em uma sociedade do conhecimento, influenciado pelas tecnologias de informação e comunicação (TIC), que trazem mudanças culturais na educação. Por meio de estudo bibliográfico, o artigo descreve as transformações culturais que vêm ocorrendo na sociedade, como o avanço das tecnologias, a velocidade com que se processam as informações, fazendo com que novas competências e habilidades se desenvolvam para construção do conhecimento. Conceitos como sociedade em rede e cibercultura se configuram para explicar a influência da Internet nesse novo contexto educacional. Ao mencionar esses conceitos, é fundamental apontar o uso dos recursos tecnológicos como ferramenta de ensino e necessidade de mudança nas práticas pedagógicas para promover o conhecimento, facilitando o processo de ensino aprendizagem. Ao apontar e conceituar esse novo paradigma cultural na educação, é necessário, também, salientar a importância que a Educação a Distância vem conquistando espaço, principalmente no ensino superior, permitindo um crescente aumento nas matrículas das instituições, configurando um novo modelo educacional que, claramente, se consolida e caracteriza a educação do século XXI. Após a descrição das mudanças que consolidam esse novo paradigma cultural na educação, fica latente a necessidade de que os educadores adquiram e apropriem-se dessas novas ferramentas de comunicação, facilitando a formação do educando nessa nova sociedade do conhecimento.

\footnotetext{
${ }^{3}$ Licenciatura em Matemática pela UFT, Mestranda Acadêmica Internacional em Educação da Universidad de la Empresa - UDE, Montevidéu - Uruguai. Seminário Culturas, Saberes y Prácticas. alderita.almeida@yahoo.com.br ${ }^{4}$ Bacharel em Comunicação Social pela UFPA, Mestranda Acadêmica Internacional em Educação da Universidad de la Empresa - UDE, Montevidéu - Uruguai. Seminário Culturas, Saberes y Prácticas. elisangelaandradebogea@gmail.com ${ }^{5}$ Licenciatura em Matemática pela Uniasselvi, Mestranda Acadêmica Internacional em Educação da Universidad de la Empresa - UDE, Montevidéu - Uruguai. Seminário Culturas, Saberes y Prácticas. pridauer@gmail.com

${ }^{6}$ Licenciatura em Educação Física pela Unisinos, Mestranda Acadêmica Internacional em Educação da Universidad de la Empresa - UDE, Montevidéu - Uruguai. Seminário Culturas, Saberes y Prácticas. vanessamoraes.profe@gmail.com
} 
PALAVRAS-CHAVE: Paradigma na Educação, Tecnologia, Cultura.

\begin{abstract}
:
The present study brings to the discussion reflections on the emergence of a new paradigm, based on a knowledge society, influenced by information and communication technologies (ICT), bringing cultural changes in education. Through a bibliographical study, the article describes the cultural transformations that have been occurring in society, such as the advancement of technologies, the speed with which information is processed, making new skills and abilities develop for knowledge construction. Concepts such as network society and cyberculture are configured to explain the influence of the Internet in this new educational context. When mentioning these concepts, it is fundamental to point out the use of technological resources as a teaching tool and the need to change pedagogical practices to promote knowledge, facilitating the process of teaching learning. In pointing out and conceptualizing this new cultural paradigm in education, it is also necessary to emphasize the importance that distance education has been gaining space, especially in higher education, allowing a growing increase in enrollments of institutions, forming a new educational model, that clearly, Is consolidated and characterizes the education of the 21st century. After describing the changes that consolidate this new cultural paradigm in education, there is a latent need for educators to acquire and appropriate these new communication tools, facilitating the education of the learner in this new knowledge society.
\end{abstract}

KEY WORDS: Paradigm in Education, Technology, Culture.

\title{
1. INTRODUÇÃO
}

As mudanças pelas quais o mundo tem passado, nos últimos anos, têm provocado importantes alterações no domínio dos costumes, do pensamento, do comportamento humano, como também nas relações políticas e econômicas da sociedade. Tais mudanças provocam consequências nas concepções de ensino e aprendizagem, assim como, na formação de docentes, no papel da escola e na relação da escola com a comunidade, gerando novas demandas, novas propostas e implicações culturais específicas.

A escola, desde sua origem formal e obrigatória, na época da Reforma Protestante (ROHTBARD, 2013), vem sofrendo influências sociais, tecnológicas e culturais. Ao mesmo 
tempo, a educação escolar gera movimentos sociais e culturais na sociedade. Se, por um lado, o ensino imposto e gratuito nasceu com a intenção reformista de modificar as mentes, que eram induzidas pela Igreja Católica (ROTHBARD, 2013), por outro lado, a própria escola, com o passar do tempo, foi se reinventando, criando novos paradigmas (VARELA, 2013).

Esses paradigmas, como: conducionista, construtivista e pós-construtivista, entre outros (VARELA, 2013), são mais voltados para a perspectiva pedagógica. Ou seja, um modelo substitui o outro trazendo novas estratégias de ensino, que podem ter como personagem principal o professor, o aluno, o próprio ensino ou a construção da aprendizagem a partir de um estudante mais crítico e autônomo. Isso vai depender de cada paradigma.

A história mostra que a evolução tecnológica da humanidade sempre esteve presente em todos os campos da sociedade, inclusive, na educação. O quadro negro, o giz, o mimeógrafo, a máquina de slide, o datashow, o computador. Todos esses equipamentos foram introduzidos nas práticas pedagógicas como ferramentas, com o objetivo de facilitar o ensino e pela necessidade de a escola e o professor se adaptarem às demandas tecnológicas de cada época.

Muito se discute sobre as tecnologias da informação e comunicação (TIC), que incluem a Internet e as redes sociais, na educação, tanto presenciais como a distância. Para Rama (2014), a educação vive um novo paradigma, baseado na expansão do conhecimento e nas novas tecnologias de comunicação. Há, portanto, uma mudança cultural na educação, que necessita de práticas pedagógicas que levem o estudante a construir seu conhecimento com 0 auxílio do professor e das tecnologias digitais e virtuais.

Pesquisas sobre o tema em questão são importantes para uma melhor compreensão das demandas atuais da educação, no que diz respeito às TIC e às transformações culturais na Era do Conhecimento atual. Portanto, este artigo, por meio de estudo bibliográfico, mostra as mudanças culturais na educação; trata dos conceitos de sociedade em rede e cibercultura; explica como os recursos tecnológicos são vistos como ferramentas de ensino e a necessidade de mudanças nas práticas pedagógicas; e, finalmente, discorre sobre a Educação a Distância (EaD), modalidade impulsionada de forma considerável pelas TIC e pela Internet e sistemas relacionados a elas. 


\section{MUTAÇÕES CULTURAIS NA EDUCAÇÃO}

O avanço da tecnologia e a velocidade com que as informações circulam exigem mudanças na forma de ensinar, atraindo alternativas de aprendizagem, que facilitem a inclusão das pessoas em todas as áreas do conhecimento e facilitem seu crescimento pessoal, tanto socialmente, como intelectualmente e, até mesmo, afetivamente.

Percebe-se uma crescente integração da cultura digital ao ensino-aprendizagem, no entanto, é notório o descompasso cultural, no que se refere à inserção, assimilação e manuseio de novas competências tecnológicas exigidas pela união de boas e novas práticas pedagógicas com as novas tecnologias. Tais mudanças vêm se configurando ao longo do tempo. Para Claudio Rama (2014), o eixo desse novo paradigma educativo está sendo construído a partir de diversas áreas de reflexão e análise, tendo como base múltiplos autores que representam os pilares do surgimento dessa mudança de fase tão significativa.

Rama (2014) cita Gibbons, na interdisciplinaridade; McLuhan, na comunicação global; Shultz, na determinação das exigências educacionais; Morin, no caráter sistêmico e diverso dos saberes; Kuhn, no caráter paradigmático das teorias; Shumpeter, na lógica da criação destrutiva da inovação econômica e social; Pérez, na complexidade da construção dos paradigmas tecnoeconômicos; Vigotsky, na diversidade interativa e da historicidade da construção do conhecimento; Piaget, na autoconstrução do conhecimento; Dewey, no pragmatismo de saberes integrados ao mercado; Taylor, no papel do multiculturalismo, na convivência e nas aprendizagens; Castells, na dinâmica de sociedade em rede; Rifikin, na lógica social do acesso digital; Tapscott, na forma digital do valor agregado do modelo econômico; Siemens, no conectivismo como aprendizagem em múltiplos ambientes, entre outros.

São todos novos enfoques educativos que impactam sobre a formação docente e que vão substituindo as práticas ideologizadas de decrescente qualidade educativa, sustentadas em burocracias educativas altamente sindicalizadas e corporativas, associadas à preservação de espaços de poder no interior das instituições públicas (RAMA, 2014, p. 34).

O sistema educativo, dentre outros sistemas sociais, é o que mais utiliza tecnologias para subsidiar o processo de ensino e aprendizagem, necessário à uma significativa mudança cultural, que vem surgindo a partir da desconstrução de velhos paradigmas e reconstrução de novos, fazendo surgir, assim, uma nova era. Schumpeter (1997) refere-se a esse fenômeno como "destruição criativa", em que ele descreve como um processo onde o que foi feito 
anteriormente é destruído a partir do momento em que é substituído por novas maneiras de fazê-lo.

Para Rama (2014), o motor contemporâneo das economias e das sociedades é dado pelo conhecimento, seu enorme nível de expansão e renovação, além das transformações que ele gera no mercado. Historicamente, os conhecimentos se constituíram como base das mudanças e da evolução social. Sempre os saberes permitiram desenvolver tecnologias, que favoreceram processos de transformação social a partir de facilitar processos mais eficazes, influenciando e exigindo que a educação também se transforme.

Os conhecimentos, enquanto motores das sociedades, têm sido o embasamento de muitas mudanças na história e, contemporaneamente, com muito mais intensidade que no passado, nas formas de produção, nas atividades e nos trabalhos, nas formas de organização das pessoas. Atualmente, o nível de expansão dos conhecimentos supera qualquer antecedente histórico, com a promoção de uma revolução tecnológica e a formação de um modelo social com características cada vez mais globalizado. (RAMA, 2014, p. 17).

Pérez (2004) corrobora com esse pensamento quando escreveu que "uma revolução tecnológica é definida como um conjunto de tecnologias, produtos e indústrias novas, capazes de abalar os alicerces da economia e de impulsionar o surgimento de mudanças sociais em longo prazo em toda a sociedade". Rama (2014) argumenta que essa revolução tecnológica está promovendo transformações em todos os processos educativos, tanto nas novas práticas pedagógicas, como, também, ao próprio sustento conceitual formado como o paradigma sobre o qual se desenvolveu a educação nas últimas décadas, e de suas formas de organização do processo de ensino-aprendizagem.

No embalo dessa nova era, onde as mudanças culturais na educação são uma realidade, há outras alternativas de construção de conhecimentos, nascidas a partir da disseminação das novas tecnologias e da Internet como meio de comunicação de massa. Uma dessas novas oportunidades é a educação a distância, modelo que se caracteriza pelo processo de aprendizagem não condicionada à presença física do educador, e que ganhou impulso a partir do acesso às novas tecnologias da informação e comunicação e à internet, conforme irá mostrar este artigo.

Historicamente a educação tem-se transformado ligada às mudanças sócio tecnológicas. Em tal curso se tem promovido novas competências de trabalho, novos campos de disciplinas, novas configurações das instituições educativas e também novos modelos pedagógicos. (RAMA, 2014, p.49). 
O novo contexto da sociedade do conhecimento promove novas formas de criação e de transmissão dos saberes (Morin, 2002). Para Rama (2014), enquanto se geram novas formas de criar o conhecimento, também se estabilizam outras formas de transmissão dos saberes: a flexibilização dos estudos, a desestruturação do currículo, a incorporação de novas competências não disciplinares, a formação de novas formas de apropriação a partir da mobilidade, a pratica ou a simulação, assim como a educação contínua, especializada e a distância.

O uso das tecnologias da informação e comunicação (TIC) também expressa o novo papel nas formas de gestão em todas as áreas da sociedade e em seu uso na própria transmissão de conteúdos codificados. A Internet favoreceu tanto a indústria eletrônica e as telecomunicações como a educação, formando o núcleo da atual convergência industrial tecnológica e o desenvolvimento de novas formas de programação e produção com base na web (MOCHI, 2001). Igualmente, a mobilidade, como parte dos processos de ensino, é uma das características da nova educação: não somente como partes de estudos comparativos, mas pela importância da diversidade de processos de ensino e a eficácia da comparação das aprendizagens.

O impacto é em toda as direções. Mudando paradigmas, nascem novas disciplinas; mudando as formas de apropriar-se de saberes, se expandem áreas de especialização já não somente disciplinar como impactam na educação enquanto área de organização dos saberes. Tudo aponta à criação de uma nova educação, a da sociedade do conhecimento, dada por um aumento e uma diversificação das demandas, à aparição de novas modalidades institucionais de transferência de saberes, pelas mudanças no espaço geográfico das instituições, pelo grau de flexibilização e mercantilização das novas modalidades institucionais, etc. neste contexto, nascem novas dimensões educativas que identificamos como a formação da educação na sociedade do conhecimento (RAMA, 2014, p. 52).

Tais mudanças tiveram consequências nas concepções de ensino e aprendizagem. O avanço da tecnologia e a velocidade com que as informações circulam exigem mudanças na forma de ensinar, logo, uma nova era se configura, de forma tão expressiva e contundente que se considera uma elevada mudança de paradigma, influenciando assim, em todas as configurações dessas mutações culturais na educação. 


\section{A SOCIEDADE EM REDE E A CIBERCULTURA}

É inegável que no século XXI se consolida uma nova era, um novo momento histórico, que faz surgir uma sociedade de informação e do conhecimento. Dois autores explicitam bem esses conceitos dessa nova sociedade. Manuel Castells (1999), com uma visão marxista da sociedade capitalista, e Pierre Lévy(1999), com pensamento mais antropológico.

Castells (1999) denomina essa sociedade como "sociedade em rede", que utiliza a internet com características e incorporações do sistema capitalista e Lévy (1998) utiliza o termo "cibercultura", conceituando-a como novo espaço de interações propiciado pela realidade virtual. Segundo os autores, atualmente, é impossível ignorar o impacto das tecnologias de comunicação à vida humana ou à vida em sociedade. Em seu livro "Cibercultura" de 1999, Lévy relata que, em uma entrevista nos anos 50, Albert Einstein declarou que três grandes bombas haviam explodido no século $X X$ : a bomba demográfica, que seria o crescimento vertiginoso da população; a bomba atômica e a bomba das telecomunicações. Esta última viria como um "dilúvio" das informações, ou seja, a explosão e o crescimento exponencial de dados, de informações.

Mas, afinal de contas, as TIC estão a serviço de que e/ou de quem? Quais mudanças são trazidas por essas tecnologias à vida do homem e à sociedade? O que desencadeou todo esse processo?

A Internet é a base da sociedade em rede, conforme indica Castells (1999). Mas, a Internet deve ser compreendida como uma rede que inclui diversos grupos de redes. E essas redes não são apenas de computadores, mas também de pessoas e de informações.

Dentro da mesma lógica da rede, essa congregação forma uma nova cultura, que Lévy denomina de cultura do ciberespaço, ou "cibercultura":

O ciberespaço (que também chamarei de "rede") é o novo meio de comunicação que surge da interconexão mundial dos computadores. O termo especifica não apenas a infraestrutura material da comunicação digital, mas também o universo oceânico de informações que ela abriga, assim como os seres humanos que navegam e alimentam esse universo. Quanto ao neologismo "cibercultura", especifica aqui o conjunto de técnicas (materiais e intelectuais), de práticas, de atitudes, de modos de pensamento e de valores que se desenvolvem juntamente com o crescimento do ciberespaço (LÉVY, 1999, p.17). 
A cibercultura se constitui, para Lévy (1999), como o principal canal de comunicação e suporte de memória da humanidade. Trata-se de um novo espaço de comunicação, de sociabilidade, de organização, acesso e transporte de informação e conhecimento.

Juntamente com esses conceitos de ciberespaço e cibercultura, Lévy relata o surgimento do termo "inteligência coletiva", em que, por meio de um novo sistema cognitivo humano, caracteriza a inteligência como não automatizada, mas reformulada e estabelecida em tempo real, formando grandes cérebros globais. Seria o modo de realização da humanidade, favorecido pela rede digital universal, sem que saibamos a priori quais resultados podem surgir a partir da conexão das pessoas em rede, uma vez que as organizações colocam em sinergia seus recursos intelectuais (LÉVY, 1999).

Para Castells (1999), a partir da década de 70, a informação e o conhecimento assumem uma nova projeção social e econômica onde as inovações e o conhecimento são as principais características da sociedade e da economia. Com esse pensamento marxista, capitalista Castells descreve os aspectos socioeconômicos da sociedade em rede. Essa sociedade que integra à lógica da sociedade em rede.

Ela originou-se e difundiu-se, não por acaso, em um período histórico da reestruturação global do capitalismo, para o qual foi uma ferramenta. Portanto, a nova sociedade emergente desse processo de transformação é capitalista e também informacional, embora apresente variação histórica considerável nos diferentes países, conforme sua história, cultura, instituições e relação específica com o capitalismo global e a tecnologia informacional (CASTELLS, 1999, p.50).

O problema dessa sociedade do conhecimento baseada em redes é que ela gera processos de exclusão daqueles que não estão inseridos nessa mesma lógica. Esses processos de exclusão, para Castells (1999), estão diretamente ligados às questões econômicas, como produtividade, inovação tecnológica, criação de redes e globalização.

A internet, mesmo sendo hoje um meio de comunicação de massa, acaba agindo como forma de comunicação personalizada. Embora, muitas vezes, reproduza padrões sociais já existentes, é inegável que a Internet transforma a sociedade em sociedade do conhecimento muito mais rapidamente que outras sociedades já configuradas na história da humanidade. Nessa nova configuração de sociedade, as fronteiras são quebradas, as identidades mudadas, as incertezas e dúvidas ressurgem a todo instante, permitindo com isso novos pensamentos, experiências e novos processos de ressignificação. 
Lévy (1999) sinaliza o papel das tecnologias intelectuais como ação positiva de acesso à informação e construção do conhecimento. O autor relata que o ciberespaço é o mediador da inteligência coletiva. Então, está posto o desafio da educação de levar em conta a existência dessa nova relação com o "saber".

Observa-se que a velocidade do surgimento e renovação desses sistemas no ciberespaço oportunizam novas configurações no mundo do trabalho, pois a construção do conhecimento inicia no campo educacional e emerge e modifica os espaços de trabalho. Para o autor, as novas formas de construir conhecimento, os novos estilos de aprendizagem, a grande velocidade das inovações tecnológicas e as consequentes mudanças no mundo do trabalho acabam questionando os modelos tradicionais de ensino baseados na transmissão de saberes e não em construção de conhecimento.

Para Lévy (1999), o ciberespaço amplifica, exterioriza e modifica funções cognitivas humanas, como o raciocínio, a memória e a imaginação.

O que é preciso aprender não pode mais ser planejado nem precisamente definido com antecedência. (...) Devemos construir novos modelos do espaço dos conhecimentos. No lugar de representação em escalas lineares e paralelas, em pirâmides estruturadas em 'níveis', organizadas pela noção de prérequisitos e convergindo para saberes 'superiores', a partir de agora devemos preferir a imagem em espaços de conhecimentos emergentes, abertos, contínuos, em fluxo, não lineares, se reorganizando de acordo com os objetivos ou os contextos, nos quais cada um ocupa posição singular e evolutiva (LÉVY, 1999, p. 158).

Situando e conceituando cibercultura e sociedade em rede, em que a informação ocupa posição fundamental no processamento e produção do conhecimento sob a ótica desses dois autores, ficará mais claro perceber quais as influências das novas tecnologias no contexto educacional. 


\title{
4. O USO DOS RECURSOS TECNOLÓGICOS COMO FERRAMENTA DE ENSINO E NECESSIDADE DE MUDANÇAS NA PRÁtICA PEDAGÓGICA
}

As tecnologias de informação e comunicação (TIC) provocaram uma mudança no cenário educacional, trazendo novos paradigmas. Não há uma resposta sobre o tipo de sistema que se faz necessário diante desse mundo globalizado e regido por informações. Analisando a tecnologia, os avanços necessitam de uma atenção de todos os profissionais envolvidos na área da educação. O ambiente escolar, que não acompanha as evoluções tecnológicas, é considerado um local conservador.

\begin{abstract}
A educação hoje não pode fugir do desenvolvimento tecnológico que embala o mundo e a vida social. Ora, as novas tecnologias da informação e da comunicação transformam espetacularmente não só nossas maneiras de comunicar, mas também de trabalhar, de decidir de pensar (PERRENOUD, 2000 p. 125).
\end{abstract}

A escola, como um estabelecimento de ensino, é comprimida pela sociedade para uma mudança no aprendizado, mas, muitas vezes, a escola se mantém no ensino tradicional. Os ambientes escolares não poderão ficar atrasados em relação a essas mudanças tecnológicas, pois a sociedade está num ritmo acelerado, num desenvolvimento de transformação tecnológica. Essas tecnologias vêm para auxiliar a sociedade na forma de estudar, de se relacionar e para o lazer. Portanto, nessa sociedade atualizada, o ambiente escolar deverá mudar as estratégias para o aprendizado, tendo uma grande responsabilidade nesse mundo globalizado.

A educação passa por grande transformação, talvez a maioria que já existiu, pois a escola deixou de ser o centro do conhecimento. Com a chegada da tecnologia, da internet, a informação passou a estar disponível a qualquer pessoa, a qualquer momento, em qualquer lugar (ALBANO, 2008, p. 45).

Os alunos têm acesso às diversas fontes de informação e comunicação existentes na sociedade em que estão inseridos, diferente das gerações passadas, que viveram num mundo sem essa diversidade tecnológica. Portanto, a escola não poderá se ocultar dessa realidade presente na sociedade, deverá reconhecer a importância das TIC como uma ferramenta para o ensino aprendizado. Valente (2008) ressalta que a escola deveria incorporar cada vez mais a utilização 
das tecnologias digitais, para que seus estudantes pudessem aprender a ler, escrever e se expressar por meio desses novos instrumentos. Ao integrar tecnologias ao processo de ensino e aprendizagem, surge um excelente caminho para promover novos conhecimentos, que permitem a inserção dos estudantes nesse novo contexto social.

Com as inovações dos recursos tecnológicos, mediante esse novo cenário mundial, onde a informação é transmitida em segundos, o professor, como mediador, tem a necessidade de compreender tais recursos para poder utilizá-los com eficiência.

Existe certa resistência de alguns profissionais sobre no uso dessas tecnologias, alguns por não terem esse conhecimento, outros por não acreditarem no potencial dessas ferramentas. Segundo Thiago Chaer:

Os educadores jamais evoluirão em sua formação e em suas práticas se não conviverem com a mudança, com novos desafios promovidos pela diversidade nas formas de aprendizado, pelo contexto singular de vida de cada educando, do seu próprio contexto e do contexto local (CHAER, p. 42, 2013).

Assim, com os avanços tecnológicos, existem diversos recursos e estratégias que estão disponíveis para auxiliar o professor em sua prática pedagógica, facilitando o entendimento do aluno, principalmente, ajudando o aluno que não tem acesso a essas tecnologias, o que torna a aprendizagem mais significativa e atraente. Para isso, o professor precisa estar preparado e ter consciência dos objetivos que ele quer atingir com a utilização do recurso tecnológico em sua sala de aula. Esse aspecto é confirmado por Bittar et al (2009), ao afirmarem que a integração da tecnologia só é possível quando o professor vivenciar o processo e quando a tecnologia representar um meio importante para a aprendizagem, destacam Ponte, Oliveira e Varandas:

Os professores precisam saber como usar os novos equipamentos e softwares e também qual é seu potencial, quais são seus pontos fortes e seus pontos fracos. Essas tecnologias, mudando o ambiente em que os professores trabalham e o modo como se relacionam com outros professores, têm um impacto importante na natureza do trabalho do professor e, desse modo, na sua identidade profissional (PONTE, OLIVEIRA E VARANDAS, 2003, p. 163)

Os alunos de hoje estão rodeados por instrumentos que os mantêm conectados ao mundo a todo instante, não têm mais como entrar numa sala de aula e ler apenas o livro didático e 
responder os exercícios propostos. A educação é um sistema social que deve acompanhar a sociedade em que está inserida.

A realidade presente é de um mundo globalizado, capitalista, regido pelas grandes potências. Os alunos que estão nas escolas, assim como deverão ser as futuras gerações, possuem um grande conhecimento extraescolar, são críticos e sedentos de saber. As aulas precisam, sim, ser envolventes, prendendo a atenção do educando e incentivando sua procura pela construção do conhecimento.

Portanto, com uso das TIC, o papel do professor vai além do ensino. O docente deixa de ser um mero transmissor de conhecimento e passa a acompanhar o desenvolvimento discente no processo de ensino aprendizagem. Isso vale para o ensino presencial e, necessariamente, na Educação a Distância.

\section{A EAD ONLINE}

A Internet e as tecnologias da informação e comunicação (TIC) associadas a ela provocaram mudanças na educação a distância. As aulas passaram a ser online, com possibilidade de realização de diversas atividades, como: fóruns, chats e videoconferências, possibilitando uma interação entre estudantes e tutores. A EaD online permitiu, ainda, um aumento no número de cursos a distância, principalmente, no ensino superior.

Segundo Valente (2003 apud BORBA, MALHEIROS E AMARAL, 2011, p. 25), "a Internet abriu um leque de possibilidades para os cursos oferecidos a distância, mudando a forma de pensar e fazer a EaD, e o grau de interação entre professor e aluno diferencia os modelos existentes".

Outra vantagem do uso das TIC na educação e na EaD online é a possibilidade de flexibilização, tanto para o estudante e para o professor/tutor quanto para as instituições. Belonni (2008) fala de quatro tipos de flexibilização: do acesso, do ensino, da aprendizagem e da oferta. A autora acrescenta que:

Os esforços de flexibilização não significam o abandono de critérios de qualidade do ensino oferecido, muito antes ao contrário, os cuidados com os critérios de avaliação devem ser redobrados para assegurar um alto grau de qualidade e credibilidade dos processos de avaliação formativa e somativa, 
especialmente para os estudantes a distância, evitando quaisquer dúvidas quanto à credibilidade e qualidade dos cursos oferecidos (BELONNI, 2008, p. 105-106).

A Educação a Distância no século XXI não pode ser separada da Internet e das TIC. Ela necessita se adequar às exigências da atualidade, do ponto de vista do uso adequado das tecnologias da informação e comunicação como ferramenta, mas também pelo ângulo metodológico. Belloni e Lapa (2012), por exemplo, afirmam que a EaD possui uma abordagem muito tecnológica no Brasil porque "cresceu (...) afastada do campo da educação" (BELLONI E LAPA, 2012, p.188).

Para compreender melhor esse contexto apontado por Belloni e Lapa (2012), e, ainda, entender e refletir sobre a EaD online e as mudanças educativas e culturais que essa modalidade vêm produzindo no século XXI, é necessário voltar às origens. Lembrando que “(...)a educação a distância aparece agora como caminho incontornável não apenas para a ampliação rápida do acesso ao ensino superior, mas também, (...) como uma nova solução de melhoria da qualidade desse ensino (...)", como ressaltou Belloni (2008) no prefácio da $5^{a}$ edição do seu livro Educação a Distância.

\subsection{Breve história da EaD no mundo}

Não há uma data exata sobre o início da Educação a Distância no mundo. No entanto, na literatura sobre o tema, há relatos de que no século XVIII, o ensino a distância já acontecia por correspondência nos Estados Unidos.

Uma das primeiras referências que temos sobre o tema é um anúncio publicado em 1728, no jornal Boston Gazzete. Nele, Caleb Phillips, professor de estenografia, apregoava que todas as pessoas que desejassem aprender esse tipo de grafia poderiam receber em sua casa várias lições semanalmente, mesmo não morando em Boston (SIMÃO NETO, 2012, p. 21-22).

Contudo, foi no século XIX que a EaD ganhou impulso na Europa e nos Estados Unidos. Alves (2011) destacou algumas datas importantes na história dessa modalidade, como: 1829, 1840, 1856 e 1892, anos em que, respectivamente, foram inaugurados, na Suécia, Reino Unido, Berlim e Chicago, instituições, departamentos e cursos de Educação a Distância.

No século $X X$, esse movimento de crescimento da EaD no mundo continuou com novidades. A partir da década de 30 , o rádio e a televisão foram incorporados à modalidade. Segundo 
Alves (2011), em "1935, o Japanese National Public Broadcasting Service inicia seus programas escolares pelo rádio, como complemento e enriquecimento da escola oficial" (ALVES, 2011, p. 86-87). Já em 1956 (ALVES), foi criada a Chicago TV College, com o objetivo de transmitir programas de cunho educativo pela mídia televisiva.

Sem dúvida, foi no século XX que a Educação a Distância se consolidou na Europa. No início da década de 1990, um acontecimento marcou essa consolidação: a implantação da Rede Europeia de Educação a Distância (European Distanceand E-Learning Network - EDEN ${ }^{7}$ ). A instituição foi criada com o objetivo de compartilhar conhecimentos e promover políticas e práticas na área da EaD, especialmente na Europa.

\subsubsection{A Ead no Brasil}

Os primeiros registros de prática de EaD no Brasil datam do início do século XX.A retrospectiva mostra que a Educação a Distância no país começou por correspondência, por volta de 1904; incorporou o rádio, a partir da década de 20; a televisão, na década de 70; e a Internet, a partir da década de 90.

Alguns momentos dessa trajetória histórica merecem destaque. Em 1939, foi criado, em São Paulo, o Instituto Monitor, o primeiro a oferecer cursos profissionalizantes por correspondência de maneira sistemática. E, em 1941, o nascimento do Instituto Universal Brasileiro, com os mesmos moldes do Instituto Monitor (ALVES). O IUB ${ }^{8}$ existe até hoje e oferece cursos profissionalizantes, técnicos e supletivos pelos Correios ou online. Com a EaD já consolidada no rádio e depois de primeiras experiências na televisão, o Serviço Nacional de Aprendizagem Comercial (Senac) criou o Sistema Nacional de Teleducação, que se transformou em Centro Nacional de Ensino a Distância, em 1995. Ainda na fase de implantação de cursos via mídia televisiva, a Fundação Roberto Marinho e a Fundação Padre Anchieta firmaram um convênio para produção do Telecurso $2^{\circ}$ grau. Com isso, pela primeira vez no país, uma rede comercial de televisão passava a oferecer curso supletivo. As aulas pela tv eram complementadas com material vendido nas bancas de revista.

Oficialmente, a EaD foi criada, no Brasil, em 1996, com a Lei de Diretrizes e Bases da Educação (Lei No 9.394). Dez anos depois, em 2006, iniciou o Sistema Universidade Aberta do Brasil, que segundo informações disponíveis no próprio Portal ${ }^{9}$ da UAB:

\footnotetext{
${ }^{7}$ Portal da Rede Europeia de Educação a Distância (European Distanceand E-Learning Network): http://www.edenonline.org/

${ }^{8}$ Portal do instituto Universal Brasileiro - IUB: http://www.institutouniversal.com.br/

${ }^{9}$ www.uab.capes.gov.br
} 
(...) é um sistema integrado por universidades públicas que oferece cursos de nível superior para camadas da população que têm dificuldade de acesso à formação universitária, por meio do uso da metodologia da educação a distância. O público em geral é atendido, mas os professores que atuam na educação básica têm prioridade de formação, seguidos dos dirigentes, gestores e trabalhadores em educação básica dos estados, municípios e do Distrito Federal.

Um estudo ${ }^{10}$ realizado pelo Ministério da Educação e Cultura - MEC, sob a consultoria de Daniela da Costa Britto Pereira Lima, mostra a expansão da EaD no ensino superior do país entre os anos de 2002 e 2012. O total de instituições públicas e privadas aptas a ofertar cursos de graduação a distância, em 2002, era de 25. Em 2012, esse número subiu para 150, sendo 80 instituições públicas e 70, privadas.

O documento, que também faz uma retrospectiva histórica da EaD no Brasil, aponta três tendências dessa modalidade: "Dividimos a trajetória da EaD no Brasil em três tendências: a de cursos por correspondência e por rádio; a do uso da televisão e de recursos multimeios; e a da utilização do computador, dos meios digitais e da internet" (LIMA, 2014, p. 15-16).

A autora do estudo analítico acrescenta, ainda, que "(...) está em curso uma tendência mais recente do uso de mídias ou dispositivos móveis, que traz a ubiquidade junto com a mobilidade, uma vez que os conteúdos do curso a distância, através do celular ou do tablet, podem estar sempre com a pessoa" (LIMA, 2014, p. 15).

A possibilidade de poder estudar a qualquer hora e em qualquer lugar, ou seja, a flexibilidade e a mobilidade, são vantagens da EaD online. Para Rama (2016), a Educação a Distância, na América Latina, encontra-se na fase da virtualização, que tem permitido um aumento nas matrículas nas instituições que usam plataformas virtuais. Há em curso um novo paradigma educacional, em que o estudante se torna mais autônomo e o professor, um tutor virtual. Criando, assim, um novo modelo de cultura na educação.

\section{CONCLUSÃO}

Conforme foi abordado neste artigo, tem-se observado grandes mudanças no mundo, nos últimos anos, provocando importantes alterações na vida das pessoas que atravessam uma fase de troca de velhos por novos paradigmas na sociedade. Observa-se que a sociedade de

\footnotetext{
${ }^{10}$ Informação disponível em: http://www.uab.capes.gov.br/index.php/sobre-a-uab/o-que-e.
} 
informação e conhecimento deve estar preparada para desvendar esses novos conceitos, assim como, para entender esse novo paradigma cultural.

Todas essas mudanças têm feito com que o setor educacional discuta e participe das importantes questões que surgem nesse novo cenário, adquirindo, assim, novas concepções de ensino e de aprendizagem. Devido à tais mutações, é perceptível a crescente necessidade de incorporação das novas tecnologias na educação. Por estarem tão presentes na vida da sociedade, os recursos tecnológicos devem ser incorporados ao ensino, não apenas como ferramentas ou como meios para ensinar, mas também como objeto de ensino e aprendizagem, que devem ser usados como novas linguagens, que causam processos cognitivos diferentes e relevantes.

Com as novas tecnologias de informação e comunicação (TIC) abrem-se novas possibilidades para uma educação que deseja se renovar. Surgem, assim, novas competências para garantir a aprendizagem, novas maneiras de implementar o trabalho pedagógico, assim como, a necessidade de uma nova postura do educador. Faz-se necessário a contínua formação dos professores para que eles possam atuar nessa nova era do conhecimento, em que as TIC servem como mediador do processo de ensino-aprendizagem.

A partir deste estudo, foi possível perceber que, nessa nova configuração da sociedade, a Educação a Distância aparece com muita força, como uma modalidade de educação adequada para atender às novas demandas educacionais que surgiram devido às mudanças decorridas ao longo dos anos. A EaD surge como uma possibilidade de se garantir acesso ao direito que todos têm à educação, utilizando-se de novos espaços de conhecimentos para garantir os direitos da comunidade por meio de um novo modelo de escola sem paredes, sem muros e com horários flexíveis. Surge, também, como uma possibilidade de reformulação dos processos educativos, que podem acontecer em espaços e tempos distintos, representando assim o desafio de construção de um novo paradigma educacional, impactando nas mudanças sociais e culturais da educação.

Conclui-se que as mutações culturais na educação são uma realidade, no entanto, a sociedade em rede e a cibercultura, o uso dos recursos tecnológicos como ferramentas de ensino e a EAD online só serão revolucionários se mudarem também os paradigmas de ensino, ou servirão, apenas, para preencher estatísticas e dizer que o ensino é moderno, não contribuindo para consolidar, de fato, a formação educacional das pessoas que estão vivendo essa nova sociedade de conhecimento. 


\section{BIBLIOGRAFIA}

ALBANO, Ricardo Sonaglio (2008) Tecnología, educación y sociedade. Algunos discursos latino-americanos. Grupo Magro. Montevideo -Uruguay.

ALVES, Lucineia.(2011) Educação a distância: conceitos e história no Brasil e no mundo. Revista Brasileira de Aprendizagem Aberta e a Distância, v. 10, p. 83-92.

BELLONI, Maria Luiza (2008). Educação a distância. - 5. ed. - Campinas, SP: Autores Associados.

BITTAR, M. et al. (2009) Integração da tecnologia nas aulas de matemática: Contribuições de um grupo de pesquisa-ação na formação continuada de professores, 2009. 14 f. Artigo (IV Seminário Internacional de Pesquisa em Educação Matemática, SIPEM) - Universidade Federal do Mato Grasso do Sul, UFMS, Mato Grosso do Sul.

BORBA, Marcelo de Carvalho; MALHEIROS, Ana Paula dos Santos; AMARAL, Rúbia Barcelos (2011) Educação a distância online. - 3. Ed. - Belo Horizonte: Autêntica Editora.

BRASIL. Lei de Diretrizes e Bases da Educação Brasileira, No 9.394. Disponível em: http://www.planalto.gov.br/ccivil 03/leis/L9394.htm. Acesso em: 01 março de 2016.

. Portal da Associação Brasileira de Educação a Distância - ABED. Disponível em: http://www.abed.org.br/site/pt/faq/. Acesso em 04 março de 2016.

. Projeto CNE/UNESCO 914brz1142.3 Desenvolvimento, Aprimoramento e Consolidação de uma Educação Nacional de Qualidade - Educação a Distância na Educação Superior.

Disponível em:

http://portal.mec.gov.br/index.php?option=com docman\&view=download\&alias=16510- $\quad$ Acesso em de 04 março de 2016.

CASTELLS, Manuel (1999). A sociedade em rede. São Paulo: Paz e Terra.

GARCIA, Anderson.(2013) Diálogos educacionais: partilhando experiências, reconsruindo conhecimento. Breno Trajano. Florianópolis. 
LAPA, Andrea Brandão; BELLONI, Maria Luiza (2012). Educação a distância como mídiaeducação. Perspectiva, v. 30, n. 1, p. 175-196.

LEVY, Pierre.(1999) Cibercultura. São Paulo: Ed. 34.

MOCHI, Alemán; PRUDENCIA, O. La producción de software, paradigma de la revolución tecnológica. Sociedad de la información y el conocimiento (entre lo falaz y lo posible). Buenos Aires: La Crujia Ediciones, 2005.

MORIN, Edigar (2002), EL método. El conocimientodelconocimiento. Cátedra: Madrid.

NETO, Antonio Simão. (2008)Cenários e Modalidades de Ead. IESDE BRASIL SA.

PÉREZ, Carlota (2004). Revoluciones tecnológicas y capital financeiro. Siglo XXI: México.

PERRENOUD, Philippe (2000). Dez novas competências para ensinar. Porto Alegre: ARTMED.

PONTE, J. P.; OLIVEIRA, H.; VARANDAS, J. M. (2003) O contributo das tecnologias de informação e comunicação para o desenvolvimento do conhecimento e da identidade profissional. In: FIORENTINI, D. (Org). Formação de professores de Matemática. Campinas, SP: Mercado Letras.

RAMA, Claudio (2010) La irrupción de nuevos modelos socioeconómicos, paradigmas educativos y lógicas económicas de la educación Universidades [enlinea], LX (JulioSeptiembre): [Fecha de consulta: 23 de febrero de 2016] Disponibleen:<http://www.redalyc.org/articulo.oa?id=37318636002>ISSN 0041-8935 Universidad de La Empresa/Magro Editores, 2014.

.(2016) MutacionesUniversitariasLatinoamericanas: câmbios em las dinâmicas educativas, mercados laborales y lógicas económicas. Montevideo, Universidad de La Empresa/Magro Editores.

ROTHBARD, Murray N.(2013) Educação: livre e obrigatória. Instituto Ludwig Von Mises Brasil. Disponível em: http://lelivros.site/book/download-educacao-livre-e-obrigatoria-murray- n-rothbardem-epub-mobi-e-pdf/, acessado em 10 de mar. 2016. 
SANTOS, Edméa. (2010)Educação online para além da EAD: um fenômeno da cibercultura. SILVA, M., PESCE, L.; ZUIN, A. Educação Online: cenário, formação e questõesdidáticometodológicas. Rio de Janeiro: Wak.

SCHUMPETER, Joseph.(1997) Empresários, Inovação, Ciclos de Ensaios. $1^{\mathrm{a}}$ ED. Celta Editora.

SIMÕES, Isabella de Araújo Garcia (2009). A Sociedade em Rede e a Cibercultura: dialogando com o pensamento de Manuel Castells e de Pierre Lévyna era das novas tecnologias de comunicação. Revista eletrônica temática. a. V, n. 5, p. 1-11.

VALENTE, J. A. (2008)As tecnologias digitais e os diferentes letramentos. Revista Pátio. Porto Alegre, RS, v. 11, n. 44, nov. 2007 / jan.

VARELA, Lopes B. (2013). Evolução dos paradigmas educacionais e "novas" tendências nas abordagens pedagógico-didáticas. Disponível em:

http://www.academia.edu/647432/Evolu\%C3\%A7\%C3\%A30 dos paradigmas educacionais e $\mathrm{n}$ ovas tend\%C3\%AAncias pedag\%C3\%B3gicas, acessado em 08 mar. 2016. 